\title{
Abordagem Histórica da Reestruturação Produtiva no Brasil
}

Marilia Salles Falci Medeiros*

Resumo: Este estudo faz uma abordagem histórica do processo de reestruturação produtiva no Brasil analisando o processo de implementação dos modelos produtivos denominados taylorismo, fordismos e toyotismo, dando ênfase as formas específicas que estes modelos adquirem no país, fazendo uma análise que vai além das questões meramente econômicas, mas sobretudo realçando os interesses políticos que sempre estiveram por trás da aplicação desses modelos, fazendo deles uma estratégia política de dominação do capital sobre o trabalho como expressão da típica maneira de como se organiza esta dominação, com os novos modelos produtivos, que iniciaram sua aplicação nos anos 80 no Brasil.

Palavras-Chave: Reestruturação Produtiva, formas de gestão do trabalho, precarização, superexploração.

\begin{abstract}
This study intends to do an historical approach to the labor restructuring process in Brazil by analyzing the implementation process of the production models called Taylorism, Fordism and Toyota, with emphasis on the specific ways that these models get in our country, making analysis that goes beyond the merely economic issues. The paper aims to highlight the political interests that have always been behind the application of these models, making them apolitical strategy of domination of capital over labor as an expression of the typical manner of how this domination is organizated with the new production models, wich began their application in 80 years in Brazil.
\end{abstract}

Key-Words: Productive restructuring, forms of labor management, precarious, over-exploitation.

\footnotetext{
* Professora Associada III do Programa de Pós-Graduação em Sociologia e Direito da Universidade Federal Fluminense (UFF). E-mail: marilia.mf@uol.com.br.
} 
Abordagem Histórica da Reestruturação Produtiva no Brasil

O objetivo deste texto é analisar o processo de construção histórica da reestruturação produtiva no Brasil. Partimos do princípio que as formas de gestão e organização do trabalho, denominados taylorismo, fordismo e toyotismo só podem ser compreendidas desde que sejam analisadas como expressões e resultado de um processo histórico, dentro das determinações do sistema capitalista, com amplas repercussões nas economias periféricas. Nossa intenção é retomar o debate teórico que existe no interior da sociologia do trabalho para compreender as especificidades na aplicação do dos três modelos de produção referidos no Brasil. Assim, nossa reflexão tem como objetivo descrever os novos padrões de relações entre capital e trabalho, privilegiando seus conteúdos políticos, buscando compreender as determinações históricas do surgimento desses modelos e o papel que eles desempenharam no processo de modernização do país.

Sabe-se que o taylorismo e o fordismo produziram novas culturas do trabalho, onde se estabeleceram determinados controles de relação de poder do capital sobre os trabalhadores, impondo racionalização na produção, disciplina e uma nova gestão na fábrica. Sabe-se também que essas práticas produtivas não ficaram somente restritas ao chão da fábrica, mas tem amplos reflexos na sociedade. Neste sentido, a disputa histórica entre capital e trabalho não só redefinem o espaço fabril como também o modo de viver, constituindo-se, como acentuou Gramsci, em um modo de vida, mais do que uma forma produtiva. São essas relações de força em cada conjuntura que determinarão o resultado ou a síntese da combinação entre capital/trabalho. (Gramsci, 1984)

O Taylorismo ou administração científica do trabalho surge como uma nova cultura do trabalho na passagem do século XIX para o século XX, nos Estados Unidos, nação que começava a despontar como potencia mundial, no que se efetivamente transformaria no pós-guerra. Período em que consolida um padrão de capitalista sustentado no industrialismo e na atuação monopolista dos capitais. O que ocorre no taylorismo, alguns autores acentuam, é um tipo de produção com bases na "expropriação do conhecimento dos trabalhadores", realizado sobre a forma de uma "gerência cientifica."

A disciplina fabril exigia uma nova relação dos homens com o tempo transformando todas as formas anteriores de sociabilidade. A disciplina taylorista tinha um forte conteúdo autoritário na sua aplicação. Era mais baseado na força e na coerção do que no convencimento e na busca da adesão dos trabalhadores. Como observa Druck é com essa dimensão que se deve compreender o fordismo. 
(Druck, 2001a) Ele não apenas representa a amplificação do taylorismo, sua difusão e consolidação.Taylor sabia que era fundamental garantir a hegemonia da gerência científica sobre outras formas de administração. Assim, para Gramsci, a organização fordista do processo de trabalho transcende o chão da fábrica, constituindo um modo de vida marcada pela racionalidade através da capacidade de comando do capital, da imposição de sua disciplina sobre o trabalho e sobre os trabalhadores. Trata-se de garantir formas de produção e de reprodução da força de trabalho que viabilizem, através da racionalização, um novo tipo humano conforme ao novo tipo de trabalho e de produção. (Gramsci, 1984)

O fordismo enquanto novo padrão de gestão do trabalho e da sociedade caracterizado pela produção em massa e pelo consumo de massa cria a necessidade de um novo padrão de renda para garantir a expansão do mercado e a inclusão dos trabalhadores. Tal inclusão era obtida com a eliminaçã da resistência dos trabalhadores pela "persuasão", sustentada essencialmente na nova forma de remuneração e de benefícios sociais. Para esa nova etapa do capitalismo tanto desenvolvido nos EUA como na Europa após a Segunda Guerra Mundial, é marcado por um crescimento e uma prosperidade econômica jamais vista, denominada pelos historiadores de "Era de Ouro do Capital". (Hobsbawm, 1996)

Como observa Harvey, esse momento histórico do capitalismo foi marcado pelo acordo entre três atores fundamentais neste processo, capital/sindicato e o Estado. Como resultado das negociações entre patrões e empregados era aceita, pelo lado dos patrões, salários altos, incorporação de ganhos de produtividade aos salários como forma dos resultados positivos da economia da época. Com a construção do Estado de Bem-Estar foram grandes os ganhos da cidadania fordista para os trabalhadores e a sociedade nos anos dourados do capital, que duram quase três décadas na Europa.(Harvey,1992)

Estas notas são importante para se analisar o Caso Brasileiro, caracterizado por um processo de industrialização tardia um com imenso exercito de trabalhadores vivendo à margem da sociedade tipicamente capitalista. São essas as características que analisaremos a seguir.

\section{Os anos 30 e o Processo de Acumulação (O Taylorismo)}

É interessante resgatar inicialmente alguns traços básicos do processo de desenvolvimento capitalista brasileiro para que possamos entender o capitalismo contemporâneo e o significado de suas mudanças no Brasil. Francisco de Oliveira inicia seu texto intitulado Crítica à Razão Dualista afirmando que a Revolução de 1930 marca um ciclo e o início de outro na economia brasileira: o fim da hegemonia agrário -exportadora e o início da predominância da estrutura produtiva de base industrial. Acentua que, ainda que essa predominância não se concretize em termos da participação da indústria na renda interna senão em 1956 ( quando pela primeira vez a renda do setor industrial superará a da agricultura), o processo mediante o qual a posição hegemônica se concretizará é crucial : a nova correlação de forças sociais, a reformulação do aparelho e da ação estatal, a regulamentação dos fatores, entre os quais o trabalho ou o preço do trabalho, têm o significado, de 
um outro lado, de destruição das regras do jogo segundo as quais a economia se inclinava para as atividades agro-exportadora e, de outro, a criação das condições institucionais para a expansão das atividades ligadas ao mercado interno. (Oliveira, 2003, p.35)

Dito de outro modo, o autor está ressaltando que, nesse momento, ocorre a introdução de um novo modo de acumulação, qualitativa e quantitativamente distinto da estrutura agrário-exportadora e que certos aspectos passam a desempenhar um papel de enorme importância. Segundo Oliveira, a regulamentação das leis em relação trabalho e capital é um dos mais importantes, se não o mais importante. ( Oliveira,2003, p.36) Isso significa que a legislação trabalhista faz parte de um conjunto de medidas destinadas a instaurar um novo modo de acumulação no Brasil. O segundo fator descrito por Oliveira é a intervenção do Estado na esfera da economia, operando e regulamentando os demais fatores, além do trabalho: operando a fixação dos preços, na distribuição de ganhos e perdas entre os diversos estratos ou grupos das classes capitalistas, no gasto fiscal com fins direta ou indiretamente reprodutivos, na esfera da produção com fins de subsídios a outras atividades produtivas. ( Oliveira ,2003, p.40)

O que está sendo analisado é o papel do Estado na medida em que ele cria as bases para que a acumulação capitalista industrial, no nível das empresas, possa reproduzir. O Estado intervém para destruir o modo de acumulação para o qual ele se inclinava. Assim, aponta Oliveira, assiste-se à emergência e à ampliação das funções do Estado, num período que perdura até os anos Kubtscheck. Regulando o preço do trabalho, investindo na infra-estrutura, impondo confisco cambial ao café, para ser redistribuído aos capitalistas industriais, rebaixando o custo de capital na forma do subsídio cambial para as importações de equipamentos para as empresas industriais e na forma de expansão do crédito a taxas de juros negativas reais, investindo na produção (Volta Redonda e Petrobras). O Estado opera continuamente transferindo recursos e ganhos para a empresa industrial, fazendo dela o centro do sistema. (Oliveira, 2003, p. 40/41).

Portanto pode-se, afirmar que foi na década de 1930 que o capitalismo no Brasil integra o que Giovanni Alves acentua como "industrialização restringida", razão pela qual alguns autores o consideram um capitalismo hiper-tardio, pois segue uma trajetória distinta dos países da Europa Ocidental e dos Estados Unidos, de caráter clássico, ou da Alemanha e do Japão, de caráter tardio. (Alves, 2000, p.104). O autor está acentuando que o processo de industrialização brasileira desenvolveu-se sob a determinação estrutural do capitalismo mundial, sem nunca ter conseguido romper sua condição de país subordinado aos pólos do capitalismo desenvolvido.

É importante enfatizar ainda, que a Revolução de 1930 vai permitir no meio industrial paulista, a aplicação do taylorismo como forma de "racionalização do trabalho" e tem como expressão a criação do IDORT (Instituto de Organização Racional do Trabalho), em 1931, por liderança do empresariado paulista.

Maria da Graça Druck enfatiza quais os interesses políticos na aplicação do taylorismo no Brasil. Segundo a autora, nesta primeira etapa, foi fundamental a política definida pelo Estado varguista para os sindicatos. O estabelecimento da nova legislação trabalhista e dos sindicatos corporativos sob o controle do Estado, 
bem como o uso da força e repressão policial para impedir as manifestações as e mobilizações que eram dirigidas pelos sindicatos livres, visava adequar politicamente as classes trabalhadores ao desenvolvimento industrial. Observa a autora:

Mais uma vez, em nome da conciliação de interesses e da cooperação entre empresários e trabalhadores, impunhase o controle sobre o movimento sindical a fim de assegurar um novo comportamento, compatível com as exigências do industrialismo .As lutas operárias contra esta nova forma de trabalho e de vida não foram controladas rapidamente. No entanto, junto á repressão policial desencadeada e as perseguições aos trabalhadores imigrantes - que estavam proibidos de exercer qualquer atividade política sindical- anunciava-se a implementação das leis trabalhistas, que tinha, por objetivo, regulamentar a força de trabalho assalariada, definindo seu estatuto, seus direitos e deveres, enfim garantindo seu uso racional.(Druck, 2001, p.56)

Os trabalhadores não receberam passivamente as repressões impostas pelo Estado, mas realizaram formas de resistência, que não podendo ter reações coletivas e públicas foram então realizadas no âmbito fabril. Dessa maneira, os atos de resistência podem ser descritos como absenteísmo, falta ao trabalho e outras iniciativas que repercutiam na baixa produtividade do trabalho. Druck descreve que a intervenção do Estado foi fundamental para a aplicação do Taylorismo no Brasil. Observa-se aí o controle do movimento sindical, que foi oficializado pelo Ministério do Trabalho, acentuando seu caráter verticalizado e corporativo. Foi necessário vencer a resistência operária através de seus sindicatos livres, colocando-os na ilegalidade, reprimindo e prendendo seus dirigentes, para estabelecer a contento, o ideário taylorista. (Druck, 2001, p. 57).

Assim pode-se concluir que a legislação trabalhista da política do Estado Varguista atendia a dois objetivos: por um lado, regulamentava o mercado de trabalho, garantindo a reprodução da classe trabalhadora e impunha limites à voracidade dos empresários brasileiros na exploração dos trabalhadores. Por outro lado, a legislação trabalhista também atendia a algumas reivindicações operárias (direito às férias,regulamentação da jornada de trabalho, folga no domingo, salário mínimo, etc.). Vargas utilizou esse expediente para ganhar a adesão dos trabalhadores ao seu projeto político.

Analisando este período, o professor Francisco Carlos Teixeira aponta que mesmo que a legislação trabalhista, mesmo que sua vigência fosse precária, como fora precária nos Estados Unidos e Europa Ocidental, no pré e imediato pósPrimeira Guerra Mundial, as bases para o seu desenvolvimento já eram conhecidas e desejadas, e, dessa forma, estavam presentes nos projetos e programas então formulados. O campo no Brasil deveria, assim, atender, de forma subordinada e dirigida pelo Estado, as necessidades que a nova regulação econômica exigia. Evidentemente, travava dois combates simultâneos (a organização do trabalho 
fabril e a libertação do trabalhador rural das peias do plantacionismo) não era um projeto político desejado. Mesmo dotado de ampla autonomia, o novo Estado deveria evitar contrariar tantos interesses ao mesmo tempo. A opção lógica era a construção de uma ampla base urbana e fabril, vivenciar os estrangulamentos da nova regulação e, a partir das cidades, ( Teixeira,1998)

\section{O Governo Juscelino Kubtscheck e a implantação do fordismo no Brasil.}

Foi no governo de Juscelino Kubtscheck que houve um grande processo de produção industrial e um vigoroso processo de acumulação de capital no Brasil. Empossado no dia 31 de janeiro de 1956. Responsável pelo Plano de Metas, tratavase de um projeto que, com auxilio do capital estrangeiro, transformaria o Brasil numa nação industrializada propondo desenvolver o projeto de "50 anos em apenas $5^{\prime \prime}$.

Acreditava-se que o Brasil não poderia mais continuar preso à produção agrícola, mas seria importante industrializá-lo. Em 1950, 60\% da população viviam no campo e somente $40 \%$ nas áreas urbanas. O projeto de base desenvolvimentista visava alterar este quadro. Para os analistas da época, o Brasil vinha passando, desde a década de 1930, por um processo não planejado de substituição de importações, e a falta de planejamento seria a causa dos constantes desequilíbrios no balanço de pagamentos. O Plano de Metas pretendia suprir essa falta, através da abertura ao capital estrangeiro, pelo investimento direto, responsabilizando o Estado na manutenção da infra-estrutura, de energia, transportes e etc.

Alves acentua:,

É a partir daí (de JK) que se constitui um novo tipo de objetivação do capitalismo industrial no Brasil, uma nova base material de acumulação do capital, adequada à lógica do capitalismo mundial do pós Segunda Guerra Mundial, que tende a restabelecer, num novo patamar histórico, a relação centro-periferia. (Alves, p.105).

Observa-se, portanto, um surto de reestruturação produtiva de 1956 a 1961, com predominância do padrão taylorista - fordista, que constituiu um novo mundo do trabalho, um novo proletariado metalúrgico vinculado às indústrias produtoras de bens de consumo durável, cujo maior exemplo é o complexo automotivo sediado no $\mathrm{ABC}$ paulista. Este se definiria como o principal setor da economia brasileira. Demos um salto para o que alguns autores definiam como a segunda Revolução Industrial

Sabe-se também que JK criou não só uma classe operária, mas também uma classe média ligada a produção de serviços e a burocracia. Mais uma vez o papel do Estado foi fundamental na condução do novo modelo produtivo fordista, para um processo crescente de acumulação no país com bases diferentes do 
modelo de industrialização varguista. Esta teve como base uma proposta nacionalista enquanto JK seguiu caminhos contrários, propondo uma industrialização brasileira baseada nas multinacionais. As empresas de capitais estrangeiros aplicavam o modelo fordista de gestão do trabalho e investiam no Brasil, pois contavam com condições ideais para a ampliação do capital. Tendo em vista a estrutura sindical atrelada ao Estado, a luta operária estava totalmente impedida ou limitada, não havendo por isso, mobilização ou atos de resistência ao modelo proposto pelas multinacionais no país.

A aplicação do modelo fordista no país difere do modelo aplicado nos países centrais e assume aqui um conteúdo diferente. Sabemos que o fordismo que se desenvolveu após Segunda Guerra Mundial tomou rumos diferentes daquele proposto por Ford no Brasil, incorporando, conforme a feliz expressão de Alain Lipietz, as "ilhas de fordismo periférico", (Lipietz,1988). Para o autor, não se trata de um fordismo autêntico, com um verdadeiro processo de mecanização acompanhado de acumulação intensiva de capital e do crescimento dos mercados de bens de consumo duráveis. É como explica o autor:

O fordismo permanece periférico no sentido de que, primeiramente, nos circuitos mundiais dos ramos produtivos, as estações de trabalho e as produções correspondentes aos níveis de fabricação qualificadas e, principalmente, da engenharia permanecem em ampla medida exteriores a esses países. Por outro lado, os mercados correspondem a uma combinação específica entre o consumo das classes médias modernas locais,com o acesso parcial dos operários do setor fordista aos bens de consumo popular duráveis, e as exportações para o centro destes mesmos produtos manufaturados a preço baixo. Assim, o crescimento da demanda social (...) por bens duráveis é por certo antecipada, porém ela não está institucionalmente regulada numa base nacional em função de ganhos de produtividade dos ramos fordistas locais

Lipietz nos chama atenção para as especificidades do desenvolvimento do fordismo e suas aplicações locais que diferem de forma acentuada da sua aplicação nos países de capitalismo centrais. As diferenças são marcantes que se comparadas com os países periféricos. Cria-se uma modalidade de industrialização combinando com formas e padrões tradicionais de produção. Este é o caso da aplicação do taylorismo e fordismo no Brasil que adquirem uma feição nacional na forma de sua gestão. E que embora descaracterizado em sua essência não deixaram de contribuir para um processo de modernização. Quanto a aplicação do fordismo no Brasil os autores são unânimes em afirmar o auge máximo da nossa modernização periférica que se deu com o golpe de 64. Foi aí que se eliminaram as mobilizações políticas e sindicais da sociedade brasileira. 
Druck acentua que "o fordismo no Brasil se consolida centralmente pela via da coerção e a força, uma vez que a ditadura iniciada em 64 põe fim às mobilizações da sociedade civil que opunham a esta força." (Duck, 2001, p. 59). Segundo Antunes, no período da ditadura militar, a superexploração do trabalho no Brasil iria assumir a sua maior perversidade histórica articulando uma jornada prolongada de trabalho com uma intensidade extenuante do processo produtivo, e uma tendência persistente á depreciação salarial, à constante subtração do quantum referente á remuneração do trabalho,, em benefício do mais-valor apropriado pelo capital monopólico."( Antunes, 1988, p.163, citado por Alves).

Também J. Humphrey vai acentuar superexploração do trabalho, como resultado de uma sociedade autoritária, esta favorecendo também no local de trabalho a não regulação do trabalho a ser regida pelo despotismo do capital. Neste momento, o Estado vai ter um papel fundamental no Brasil, na medida em que vai se tornar o árbitro para a construção de uma sociedade regida por leis ditatoriais, resultado de um governo autoritário e de exceção. Desta forma, vivemos um longo processo de repressão, onde todo e qualquer modelo que não seguisse aos interesses políticos e econômicos ditado pelo Estado e atrelado aos interesses do capital estrangeiro, eram caracterizado como oposição aos interesses nacionais. Neste sentido, tivemos como resultado no país aplicação de um modelo "fordista" descaracterizado, no qual não se criou um Estado de Bem-Estar como nos países desenvolvidos, no qual pudesse incorporar amplas massas de trabalhadores à cidadania fordista.

Como o desemprego faz parte da estrutura produtiva brasileira, não se conseguiu como nos países centrais, o pleno emprego. Isto é, a integração de grandes parcelas de trabalhadores ao trabalho industrial, resultando com isso, amplas parcelas da populações, fora das benesses que do desenvolvimento, incluídas nos setores tradicionais da economia. Estes trabalhavam sem vínculo formalizado e sem salários definidos. O setor industrial no Brasil, não foi suficiente para incorporar todos ao modo de produção fordistas, gerando uma estrutura produtiva e uma gestão da classe trabalhadora bem diferentes dos países centrais. Sabe-se que o salário desempenhara uma função fundamental, na medida que funcionava também como elemento de persuasão da classe trabalhadora e permitia sua integração ao consumo de massa.

Nosso caso brasileiro, isso não se deu, ao contrário, não criamos uma sociedade de consumo tendo em vista o baixo poder aquisitivo dos trabalhadores. Historicamente os salários sempre foram baixos no Brasil e se observa que, no período fordista, não se regulou os salários levando-se em consideração os ganhos de produtividade como nos países centrais. Druck acentua as características de nosso Estado autoritário, a ausência de organização sindical em funcionamento, que contribuiu para fortalecer no Brasil o uso da força de trabalho essencialmente predatório. A autora constata com dados oficiais que no referido período havia extensas jornadas de trabalho, o não pagamento de horas extras, grande rotatividade da mão de obra, falta de treinamento e investimento em qualificação de mão , instabilidade no emprego, falta de registros e de contratos, sem contar os baixos níveis salariais usado pelo empresariado no Brasil.( Druck, 2001a, p.61) 
Estávamos longe de conseguir o pleno emprego, estabilidade no trabalho e a criação de um Estado de Bem-Estar devido à ausência de um ambiente democrático como o existente nos países desenvolvidos. A classe operária viveu nos anos 70 no Brasil o auge de um governo autoritário e ditatorial, que impedia manifestações de resistência. Por isso, como acentuou Carvalho, "combinou-se a intensificação do trabalho com a contenção salarial." (Carvalho, apud Druck ,2001a , p. 62)

\section{Crise do fordismo}

Muito já se escreveu sobre a crise do fordismo nos países centrais,cujos indicadores começaram a aparecer no início dos anos 1970 e se constataria uma forte desaceleração do crescimento econômico pondo em crise o sistema nas nações centrais do sistema. Para Harvey no período de 1965 a 1973 se percebe a incapacidade do fordismo e do keynesianismo de conter as contradições inerentes ao capitalismo. A crise do fordismo, que hoje já faz parte de um debate teórico e histórico, tem para Harvey explicação no que o autor define como a rigidez. Havia problemas com a rigidez dos investimentos de capital fixo de larga escala, rigidez dos mercados de consumo e de contratos de trabalho, a rigidez dos compromissos do Estado, intensificado com os programas de assistência e seguridade social. (Harvey , pp.135/136)

Enquanto que no contexto internacional manifestava-se uma situação de crise do capitalismo, o Brasil de 1968 a 1973 alcançaria grandes índices de crescimento econômico. Este crescimento era o resultado do que se denominou na época de "milagre econômico brasileiro", que estava baseado na produção de bens de consumo duráveis. Foi no $\mathrm{ABC}$ paulista que se instalaria um dos principais pólos industriais do país, dando origem ao que se denominou de complexo automotivo brasileiro. A realidade deste momento de industrialização brasileira era completamente diferente do que ocorria países centrais. O que estava ocorrendo lá fora era um processo de profunda reestruturação produtiva como estratégia do capital para sair da crise que afetava rentabilidade do capital, chegando alguns autores a denominar de Terceira Revolução Industrial. Esta mudança de paradigma produtivo, impondo novos padrões flexíveis de produção estava sendo inspirados no toyotismo. Como aponta Antunes, o toyotismo é um sistema de organização da produção e do trabalho criado pela Toyota. O toyotismo tem tido um impacto extraordinário, enquanto processo ágil e lucrativo de produção de mercadorias. (Antunes, 1995, p.27)

Como um modelo produtivo $\mathrm{n}$ só foi aplicado nas grandes corporações onde as relações de trabalho são mais organizadas e permite melhores condições de trabalho na busca de envolvimento do trabalhador por produtividade. O processo de industrialização no Brasil atinge seu ponto máximo no período de 1968 a 1973 onde já começam a observar o declínio dos níveis de acumulação, mas indicadores só seriam percebidos na década seguinte Os autores apontam para 
uma crise do setor de produção de bens duráveis, (eletrodomésticos, automóveis e etc.).

Para Alves, esta crise não foi gerada pelo esgotamento no padrão de organização do trabalho intensivo baseado nos princípios taylorista - fordista, foi uma crise no padrão de industrialização retardatária :

\begin{abstract}
No período do Estado desenvolvimentista, a industrialização retardatária, comandada pelo capital internacional, voltava-se para o mercado interno, protegido pela reserva de mercado, com oligopólios internacionais (e nacionais) conseguindo elevado patamar de lucratividade (principalmente em suas relações de promiscuidade com o Estado). ( Alves, 2000, p.110)
\end{abstract}

O autor explica que, naquele período, era possível constatar, em seu desdobramento histórico, uma contradição entre industrialização voltada para o mercado interno e a nova etapa da economia capitalista mundial caracterizada pela internacionalização do capital. Nos anos 1980 manifesta-se, abertamente, a deterioração da economia capitalista no país, gerando hiper-inflação, recessão e a crise da dívida externa (1981-1982), contribuindo para debilitação da economia do pais.

A economia brasileira foi colocada diante da necessidade desesperada de novos saldos na balança comercial visando adquirir meios de pagamentos internacionais para cumprir o serviço da dívida externa. Pela imposição dos ajustes ortodoxos do FMI, com a tutela dos credores internacionais, o país se concentrou no equilíbrio do balanço de pagamentos adotando, para isso, políticas recessivas que deixam o circuito interno do capital paralisado. Ocorreu a deterioração do setor público, que se debilitou ainda mais, paralelamente á deterioração das condições sociais. (Alves, 2000, p. 112).

\title{
A reestruturação produtiva no Brasil
}

Vários estudos apontam para a crise dos anos 1980 e enfatizaram a crise no padrão do uso do trabalho. (Gitahy,1983; Leite, 1994; Carvalho, 1987). Os autores acentuam não somente a crise econômica, mas também dois outros fenômenos que se deve relevar na análise desse período: o ressurgimento do movimento sindical e o processo de abertura política que se inicia no país. Esses fatores teriam uma importância grande na medida em que atuam no sentido de incentivar as empresas e até mesmo pressionar no uso de formas menos autoritárias de gestão do trabalho. Assim, uma reestruturação produtiva começava a surgir no Brasil como alternativa produtiva e que traria muitos problemas e 
conflitos no processo de sua aplicação. A reestruturação realizada no Brasil teve duas características como aponta Leite:

Em primeiro lugar, embora as estratégias seguidas pelas empresas em cada um desses momentos sejam bastante diferenciadas, um elemento comum é o seu caráter limitado e reativo,ainda que não se possa deixar de considerar que alguns setores mais competitivos,como o automobilístico, venham a apontando para um processo mais sistêmico; em segundo, ao contrário das expectativas dos estudos iniciais quanto mais o processo se aprofunda, mais nocivos se mostram seus efeitos sociais. (Leite, 2003. p.70)

O início do processo de reestruturação produtiva começa no Brasil em finais dos 1970 e início dos anos 1980. A inovação aqui se deu na aplicação dos Círculos de Controle de Qualidade (CCQs), que pressupões uma empresa que tenha um gestão da força de trabalho mais democrática do que a que existia no Brasil. Autores apontam para aplicação das técnicas japonesas no Brasil, ressaltando a resistência dos gerentes de empresa em delegar decisões aos operários. Hirata mostra que os CCQs estavam sendo deformados no Brasil tendo em vista que não se mudou o esquema das relações de poder dentro das empresa. Leite realça o conteúdo político de muitas propostas do CCQs. Sua aplicação no Brasil se deu após o vigoroso processo de mobilização operária que marcou o final dos anos 1970, coincidindo com o fortalecimento da organização dos trabalhadores nos locais de trabalho e a constituição das comissões de fábrica.

Nesse sentido aponta:

“Os CCQs foram introduzidos em muitas empresas a partir da preocupação gerencial em desviar o ímpeto participativo dos trabalhadores para formas alternativas de organização que contasse com maior controle gerencial." (Leite, 2003, p.72)

Sabe-se que os trabalhadores perceberam a estratégia empresarial em aplicar os CCQs e os sindicatos os mais combativos passaram a se opor levando ao fracasso na aplicação da técnica, obrigando aos empresários a dirigirem para outras técnicas. Não só a oposição dos trabalhadores a aplicação dos CCqs foi suficiente á sua retirada ,mas também a resistência das empresas em dotar gestão mais participativa talvez tenha sido um dos maiores entraves na aplicação da técnica empresariais que exigiam maior envolvimento dos trabalhadores. 


\section{O segundo momento da reestruturação produtiva no Brasil - Os Anos $1980 / 1990$}

O Brasil superando a forte recessão econômica dos primeiros anos da década, a retomada do crescimento propiciou a difusão de novos equipamentos industriais e as empresas buscaram novas formas de organização do trabalho, baseado nas técnicas japonesas. Começa, sobretudo, sua aplicação pelos setores de ponta da economia, tendo em vista a fraca motivação do empresariado brasileiro em aplicar as inovações organizacionais. Estas eram as grandes empresas exportadoras que tinham não só a liderança econômica como também surgia um forte movimento sindical. Muitos estudos apontam para a liderança do complexo automotivo, constituído pelas montadoras, autopeças, bens de capital. Embora apresentasse já um esforço inovador no que tange a modernização dos equipamentos técnicos, nossa defasagem ainda era muito grande se comparado com o mesmo setor instalados nos Tigres Asiáticos e até mesmo o México. Tínhamos os menores índices de robotização e menores porcentagens de automação. (Leite, 2003)

No que se refere à reestruturação organizacional, os estudos apontam para aplicação de um processo de caráter "defensivo" tendo em vista a cultura do empresariado nacional em não permitir maior participação dos trabalhadores nas decisões da empresa, esta com uma gestão marcadamente autoritária. Nesse cenário, as técnicas japonesas baseada na aplicação de trabalho de grupo, onde se daria maior autonomia aos trabalhadores no Brasil, encontraria resistência se chocando com o caráter autoritário das empresas produzindo mudanças muito pouco significativas na organização do trabalho. ( Leite, 2003). Usando a expressão de Salermo, "o modelo japonês" no Brasil deixa de ser japonês para tornar-se nissei", tendo em vista a ausência de autonomia dos operários na definição dos métodos de trabalho dos operários.( Salermo,1985)

Esta "brasilianização" produziu mudanças muito pouco significativas na organização do trabalho, tendo em vista as dificuldades na difusão de esquemas participativos dos trabalhadores nas empresas. Isso resultará em uma forte inércia nas empresas brasileiras, por manterem os esquemas tradicionais, desestimulando tomadas de decisão em grupos de trabalho, dificultando o trabalho em equipe. (Posthuma,1990 e Ferro,1992, citada por Leite, 2003). Os benefícios da aplicação das técnicas japonesas no Brasil só seriam possíveis atingir se houvesse a reformulação das relações capital/trabalho se fizesse presente. (Hirata, 1992)

A principal característica das mudanças produtivas, que Giovanni Alves as denomina como "novo complexo de reestruturação produtiva", é a sua debilidade em instaurar uma nova hegemonia do capital na produção, tornando-se incapaz de realizar as promessas "integracionistas do espírito do Toyotismo. Alves trabalha com a categoria da superexploração do trabalho dando ênfase ao antagonismo de classes que debilitavam um dos principais intentos do toyotismo: promover a direção moral-intelectual do capital na produção, articulando o consentimento 
operário e o controle do trabalho, capaz de realizar a subsunção da subjetividade operária á lógica do capital. (Alves, 2000, p.159).

O autor analisa o processo de super-exploração do trabalho, que já faz parte da cultura do empresariado brasileiro, além de acentuar também a debilidade da organização dos trabalhadores, com sindicatos em grande parte de sua história atrelado ao Estado no Brasil. São estes fatores que vão contribuir enormemente para a permanência da superexploração no país. Com a reestruturação produtiva e com um enorme desemprego que a caracterizou os anos 1980 se observa-se mais uma vez a convivência de um novo modelo produtivo e com uma nova forma de super-exploração. No Brasil, o neoliberalismo se caracterizou pela precarização do trabalho não elevando os salários reais e com a debilitação dos sindicatos , produzido fundamentalmente pelo desemprego. Estas condições permitem se conviver com um enorme arrocho salarial nos anos 80 . Segundo o autor esta super-exploração estava centrada na automação microeletrônica e convivia com uma nova organização do trabalho permitindo altas taxas de lucro, através de uma nova "rotinização do trabalho". (Alves, 2000. p.105/106). São estas condições de trabalho e a o intenso arrocho salarial que vão influenciar a grande mobilização operária deste período. É o que observou Antunes:

"A degradação salarial intensa e extenuante obriga ao movimento operário, através da ação sindical e grevista, a acentuar o eixo da sua ação neste universo, a centrar o eixo de sua ação neste universo." ( Antunes ,1990.p.34)

Leite destaca ainda o fraco investimento em treinamento, bem como o baixo nível educacional da força de trbalho empregada pelas empresas. Os esforços empresariais destinados ao treinamento eram nesta década de 80 ainda muito pouco expressivos., em consonância com as altas taxas de rotatividade. (Leite, p76). Como aponta a literatura, outro aspecto enfatizado é a resistência das empresas em abandonar as políticas salariais baseadas em complexas estruturas de cargos e salários, voltadas a dividir os trabalhadores e estabelecer a competição entre eles. As empresas se recusavam a contratar trabalhadores multifuncionais tendo em vista que teriam que pagar um salário superior às demais categorias de trabalhadores. Neste sentido, preferiram abrir mão destes trabalhadores multifuncionais a ter que aumentar significativamente os salários. ( Leite, p.77/79) Pode-se concluir, portanto, que na década de 80 , neste complexo descrito pela literatura, que houve uma enorme resistência por parte do patronato em transformar de forma profunda as políticas empresariais de gestão do trabalho.

Nádya Guimarães acentua que as mudanças mais importantes deste período não foram realizadas dentro da fábrica, pelas novas tecnologias, mas pelas lutas do movimento sindical que, neste período, foram muito significativas no mundo operário. Deve-se acrescentar ainda que esta década marca ainda mudanças políticas institucionais altamente significativas para o Brasil, decorrentes 
do processo de redemocratização do país que certamente afetaria às relações de trabalho. ( Guimarães, 1993)

Não podemos deixar de mencionar que, nesta década, sindicalistas, intelectuais e representantes do movimento popular fundam o Partido dos Trabalhadores, com a proposta de estabelecer um governo que represente os anseios da classe trabalhadora. Surge, também, a mais expressiva liderança sindical brasileira: Luiz Inácio da Silva, o Lula, que vinte anos mais tarde seria o presidente do país.

Com o surgimento das Comissões de Fábrica estas contribuíram para diminuir o despotismo tradicional nas fábricas, melhorando o relacionamento entre operários e chefias. Isto era o resultado da grande militância sindical contra ao arrocho salarial daquele período, e não o espírito do toyotismo que tivesse sido plenamente realizado no país. O que se pode concluir é que nos anos 80 , com a forte presença dos sindicatos nas portas das fabricas, tenha- se observado algumas mudanças nas relações de trabalho: menor rotatividade dos trabalhadores, diminuição das demissões arbitrárias e menos despotismo nas relações de trabalho, pelo menos nas industrias automobilísticas. Alves aponta para as mudanças na indústria automobilística onde as mudanças nas relações de trabalho vão ser significativas naquele período,

\section{Os Anos 1990: A reestruturação produtiva e a entrada do Brasil no neoliberalismo.}

Os anos de 1990 marcam uma redefinição da conjuntura internacional, com a crise do capitalismo iniciada nos anos 1970 exigiu-se uma nova organização econômica e política. A crise como já foi descrita acima não só exigiu uma reestruturação do paradigma técnico produtivo tendo em vista o esgotamento do fordismo. Ressalte-se ainda que em 1989, com a queda do muro de Berlim, o mundo observa uma grande crise dos países socialistas. Como expressou Octávio Ianni:

“ (...) A queda do Muro de Berlim não só simboliza a crise dos regimes socialistas, mas também a abertura de novas fronteiras para a expansão do capitalismo para os países do Leste Europeu. (...)." ( Ianni,1992.p12)

Isso representou o fim de uma longa etapa histórica que dividiu o mundo em países socialistas e capitalistas. Terminou a Guerra Fria e o capitalismo seguiu, a partir desta etapa, a desempenhar uma hegemonia internacional. Segue-se um reordenamento entre as nações mundiais. Com a crise gerada com o esgotamento do fordismo e o Fim da Guerra Fria, os Estados Unidos despontam como nação hegemônica. Neste sentido incentiva a aplicação de políticas de cunho neoliberal como forma alternativa para sair da crise. 
Como observa Druck, as políticas de cunho neoliberal já vinham sendo aplicadas, mas agora o projeto neoliberal dá uma nova direção e consegue articular os países do centro redefinindo as suas relações . Podemos distinguir dois períodos no Brasil da era neoliberal: o período do governo Collor ( 1990-1993) e o período do governo de Fernando Cardoso, a partir do Plano Real, em 1994, quando se estabelecem, com maior eficácia política, as novas bases da reestruturação produtiva no país. (Druck, 2001a)

No final da década de 1980, o governo brasileiro deu início à reforma comercial com a eliminação dos controles quantitativos e administrativos sobre as importações somado a proposta de redução tarifária. Para Rego e Marques, a abertura da economia brasileira intensificou-se a partir de 1990. O esgotamento do modelo de substituição de importações e a crescente desregulamentação dos mercados internacionais contribuíram para uma reestruturação da economia brasileira, influenciada pela redução das tarifas de importação e eliminação de várias barreiras não-tarifárias. No Governo Collor, teve início o mais radical processo de abertura comercial já registrado desde pelo menos a chamada mudança do eixo dinâmico, nos anos 1930, brilhantemente descrito por Celso Furtado em sua obra Formação Econômica do Brasil. As alíquotas médias passaram de 30,5\% em 1989 para 32,2\% em 1990. Baixaram para 25,3\% em 1991 e reduziram mais ainda para 20,8\% em 1992, último ano de governo efetivo de Collor de Mello que sofreu processo de impeachment em outubro de 1992, devido às denúncias de corrupção num ambiente de completo fracasso do Plano Collor II. (REGO, J MARQUES, R. 2000, p. 184.)

O governo Collor é caracterizado pelo sentido inercial dos horizontes de valorização no Brasil. A recessão, decorrentes das medidas de estabilização macroeconômica por meio de juros altos e controle da liquidez, o Plano Collor, foi uma das mais profundas da história da República. Em 1990, o PIB atingiu um dos patamares mais baixos desde 1981 ( menos 4,28 \%). Em 1991, o PIB foi 1,08 \%;e em 1992 houve uma queda de o,83 \% ( Folha de São Paulo , maio 1991, citado por Alves, p.195)

Segundo Alves a abertura comercial criou um cenário de crise para a indústria brasileira, especialmente no setor automobilístico, que durante muito tempo se beneficiou de um mercado interno protegido. A partir do governo Collor a indústria automobilística perdeu toda uma série de incentivos, criados no período da "industrialização substitutiva". O programa de Collor propunha ainda cortar investimentos, promover programas de demissões e reduzir salários. O cenário da economia brasileira sob o governo Collor foi caracterizado pela recessão, crescente desemprego industrial, criando as condições políticoideológicas para o desenvolvimento do toyotismo.

\section{A ampliação do modelo japonês e o neoliberalismo do governo de FHC}

Na sociologia do trabalho há também um debate sobre a aplicação do modelo japonês no Brasil. Grande parte destes estudos analisam o processo de estruturação do novo paradigma produtivo, qualitativamente diferente do 
taylorismo e fordismo, Mostram que também o Toyotismo sofre no Brasil aplicação de forma peculiar seguindo rumos muito diferentes daquele usado nos países de origem, o Japão e os demais países desenvolvidos. Tal como o taylorismo e o fordismo periférico, o toyotismo adquire formas nacionais. Contudo, os estudos enfatizam que não há uma ruptura com o taylorismo/ fordismo no Brasil, mas uma convivência destes modelos com as novas formas flexíveis de produzir advindas do toyotismo. Isto nos remete a pensar que não houve aqui um esgotamento do modelo fordista. Não houve uma crise do fordismo em termos da resistência dos trabalhadores aos métodos de gestão como nos países centrais do capitalismo, mas um fordismo que não se completou na sociedade brasileira.

O resultado é que entramos em um processo de reestruturação produtiva, aplicando um novo paradigma de forma bem diferente daqueles usados pelos países centrais. Enquanto nestes países a aplicação do modelo japonês visou os desafios da qualidade, segurança e produtividade no Brasil este modelo foi aplicado visando a redução dos custos na produção. Outro fator que não pode deixar de ser citado é a pressão da concorrência entre os capitais força o empresariado nacional a lidar com as novas bases da competitividade.

Há autores que chamam nossa atenção que o fator político também pode ter influenciado fortemente o empresariado brasileiro a criar novas estratégias produtivas. Assistiu-se nos anos 1980 uma significativa mobilização operária, que culminou com a fundação da CUT e do PT em São Paulo . Outras formas de resistência operária também vão influenciar o patronato, na medida que aparecem nas fábricas movimentos como operação tartaruga ,absenteísmo, e outras práticas que mostravam a insatisfação dos operários.

Humphrey acentua:

Assim, há que se levar em conta este fator essencialmente político, a determinar também novas estratégias empresariais. As políticas de gestão baseadas na Qualidade Total e na terceirização procuraram ,sem nenhuma dúvida, romper com este quadro,desestruturando os coletivos do trabalho, estimulando a concorrência entre os trabalha, ao mesmo tempo que buscaram o envolvimento e a colaboração dos empregados." ( Hamphrey, 1989, p. 119)

Aqui, está sendo analisado o combate contra os sindicatos, contra o coletivo dos trabalhadores e contra qualquer fato de oposição à empresa. Não se pode então negar que a reestruturação segue também um forte conteúdo ideológico, tendo na flexibilização uma forma de controlar as resistências e lutas dos trabalhadores. ( citado por Druck p.119)

Com a ascensão de Fernando Henrique Cardoso que toma posse em 1995 e governa o país até 2003, através de uma aliança do PSDB com o PFL, as políticas neoliberais foram intensificadas. O processo de liberalização econômica e as privatizações das empresas estatais foram a marca deste governo. Segundo 
Mattoso a abertura comercial indiscriminada, a ausência de políticas industriais e agrícolas, a sobrevalorização do real e os elevados juros introduziram um freio ao crescimento do conjunto da economia e uma clara desvantagem da produção doméstica diante da concorrência internacional. A reação das empresas, dada a menor competitividade diante dos concorrentes externos foi imediata: aceleraram a terceirização de atividades, abandonaram linhas de produtos, fecharam unidades, racionalizaram a produção, importaram máquinas e equipamentos, buscaram parcerias, fusões ou transferência de controle acionário e reduziram custos, sobretudo da mão-de-obra. (Mattoso, 2001, p. 30)

Tal processo sócio-econômico foi ilustrado através dos dados apresentados pela pesquisa das taxas de desemprego na região metropolitana de São Paulo (PED) elaborado pelo convênio SEADE/DIEESE, MTE/FAT, onde podemos observar que a taxa de desemprego total saltou de 8,7\% em 1989 para $13,2 \%$ em 1995 e para 19,3\% em 1999, ilustrando com veemência que nada menos de um milhão e setecentos e quinze mil pessoas estavam sem emprego em 1999. No âmbito de toda a federação, os dados apresentados pelo IBGE, referentes ao desemprego aberto brasileiro, nos informam que este mais do que dobrou na década, saltando de 3,64\% em 1989 para 8,01\% em 1999. A brutal elevação do desemprego e o paralelo processo de precarização das relações do trabalho reascenderam a discussão acerca da categoria clássica "exército industrial de reserva".

Ocorrem importantes mudanças na base eletrônica industrial, com introdução intensa da automação industrial e informática. Observa-se uma erupção da flexibilização do contrato de trabalho, cujo desdobramento legal é a Lei do Contrato Temporário de Trabalho, promulgada pelo governo Cardoso em 1998 e cujo principal objetivo é constituir novas estratégias de racionalizações de custo da produção capitalista no país. Essas mudanças já produziram um amplo debate teórico e crítico na sociedade, no qual são os autores unânimes em afirmar que resultaram em fortes perdas insegurança para os trabalhadores. ( Borges, p.80).

No que se refere ao mercado de trabalho essas medidas marcam um quadro de regressão, precariedade e terceirização. Esta última assume diversas formas subcontratação, além do aumento do trabalho autônomo, da desregulamentação das relações de trabalho, impondo a flexibilização. Foi este o legado do FHC trouxe para a classe trabalhadora, como observa Ângela Borges:

Nos governos Fernando Henrique Cardoso ocorreram tanto conivência com a burla da legislação trabalhista , explícita na fragilização dos órgãos fiscalizadores e na não punição dos infratores, como diversas mudanças na legislação,como a flexibilização da já flexível contrato temporário,o banco de horas, o contrato em tempo parcial, a regulamentação das cooperativas de trabalho,dentre outros muitos casos apenas para legalizar as práticas ilegais que já vinham sendo toleradas. (Borges,2007,p.84) 
É importante observar que a desregulamentação das relações de trabalho ainda está em processo de mudança para atender aos interesses do ambicioso patronato industrial, que inclui a extinção da CLT, e direitos históricos que o trabalhador brasileiro adquiriu: férias remuneradas ,jornada de trabalho de oito horas, licença maternidade deixariam de ser direitos assegurados por lei e passariam a ser negociado com o patrões. Este conjunto de transformações no mercado de trabalho, acrescido desemprego estrutural elevadíssimo, permite maior intensificação da jornada de trabalho e retira direitos que o que historicamente se conseguiu no Brasil. Com isto podemos concluir que o Governo FHC foi praticamente a negação do governo Vargas, desmontando estruturas históricas e acentuando os elementos mais precários e desumanos do mercado de trabalho no Brasil.

\section{Conclusão}

Para concluir, serão necessárias algumas observações sobre os dois governos do Presidente Luiz Inácio Lula da Silva. Para Filgueira e Druck, a eleição de Lula para a Presidência em 2002 representou a possibilidade de uma redefinição ou, até mesmo, uma ruptura com as políticas neoliberais. No centro da expectativa estava à possibilidade de superar a crise do desemprego e do mercado de trabalho no país, através de um novo modelo econômico no qual a implementação de políticas de emprego e renda teria lugar central em sua gestão. ( Druck e Filgueira, 2007b)

O governo Lula, contrariando a origem da história do $\mathrm{PT}$, não pode realizar essa ruptura, tendo em vista a política de alianças com partidos de centro e esquerda, contrariando as principais lutas e reivindicações dos trabalhadores brasileiros. A atuação do Estado vai ser fundamentada na lógica do capital financeiro que, como observa Druck e Filgueiras

(...) para além do campo estritamente econômico, propaga-se para todas as dimensões da vida social, sustentada nas idéias de volatilidade e de flexibilidade,como valores e ideologia e que fundamenta a ideologia do Estado. Combinam-se neste contexto perfeitamente a flexibilização e precarização do trabalho e as políticas focalizadas e flexíveis de combate a pobreza. Ambas regidas pela mesma lógica, qual seja, de curto prazo, do imediatismo inconseqüente, de intervenções pontuais e precárias que, para não se contrapor à ordem Mundial, subordinam-se ao reino da volatilidade, sem mudar e intervir sobre as causas estruturais dos problemas fundamentais da sociedade brasileira. (Druck e Filgueiras, 2007b, p.3). 
Embora alguns autores ainda constatem que no governo Lula ainda se mantém elevada as taxas da informalidade, os salários ainda continuam baixo é inegável que está se processando uma melhora de muitos índices da sociedade.

Claudio Salvadori Dedeca nos mostra que "uma dimensão surpreendente da recuperação econômica no período recente tem sido sua capacidade para recompor o mercado formal de trabalho. Esse movimento contraria a visão apocaptica sobre a desaparição do mercado formal de trabalho amplamente veiculada nos anos 1990 e utilizada como argumento para justificar uma suposta naturalização do crescimento do desemprego no período. Dedeca compara os dados de 1995-1998 e 2002-2004.

Para o autor houve um significativo crescimento em 2002-2004. $752 \mathrm{mil}$ postos de trabalho foram criados contra 4,5 milhões entre 2002-2004. Este crescimento mostra uma forte discrepância entre os dois períodos. Para o autor a elasticidade produto-emprego é mais acentuada na recuperação atual, como tem efeitos mais positivos para a formalização dos contratos de trabalho. ( Dedeca, 2007, p.116)

No final de 2004, o governo Lula adotou uma iniciativa positiva ao instituir o Conselho Nacional do Salário Mínimo, com o objetivo de formular uma política de sua valorização. Também, sinalizou com a criação de uma Comissão Tripartite com o objetivo de apresentar diretrizes para uma política de valorização do salário mínimo. Estas medidas mostram a nova atitude do governo no que se refere ao tema, que é muito diferente do governo FHC. No início do atual Governo, o salário mínimo comprava 1,4 cestas básicas (valor médio nacional segundo o DIEESE). Com o reajuste para $R \$ 465$, 00 , o seu poder aquisitivo cresceu para 2,3 cestas básicas (+64\%) em julho/2009.

O valor do salário mínimo de $\mathrm{R} \$ 465,00$ fixado para vigorar a partir de fevereiro de 2009, equivale a $R \$ 178,41$ em termos de valor da moeda nacional que vigorava em maio de 1995. Esse valor implica em um ganho real de mais de $70 \%$, quando comparado com o vigente em maio de 1995, primeiro ano do Governo FHC. A elevação do salário mínimo acima da inflação, a ampliação da acessibilidade ao crédito e a redução do desemprego associado às políticas públicas, como o Bolsa Família - parecem ter sido os principais fatores do aumento do consumo das famílias no Brasil, entre 2004 e 2009. Houve um aumento no consumo de bens duráveis e semiduráveis, como automóveis e eletro-eletrônicos. Os dados mostram ainda uma redução das desigualdades sociais, segundo pesquisadores do IBGE, devido aos programas de distribuição de renda como, por exemplo, a cobertura mais universal da aposentadoria do INSS, e o Programa Bolsa Família.

Segundo esses indicadores, podem-se fazer projeções mais otimistas para a próxima década. De 2003 a 2008, a renda dos 10\% mais pobres aumentou $8 \%$ ao ano, enquanto os ganhos dos ricos cresceram 1,5\%. Durante muito tempo, essa equação estava invertida na lógica capitalista brasileira. Agora o abismo social, que ainda é grande, está enfim sendo combatido.

O emprego é fundamental para a ascensão social das classes populares e no governo Lula de janeiro a julho de 2010 foram criados no país 1,6 milhões de novos postos com carteira assinada, um recorde para o período desde que o Ministério do 
Abordagem Histórica da Reestruturação Produtiva no Brasil

Trabalho começou a fazer a contagem, há 20 anos. Em uma década o Brasil gerou 15 milhões de empregos. Associe-se a isso o aumento gigantesco do crédito, que em oito anos acrescentou mais 1 trilhão à economia brasileira, e o cenário que se constrói é de uma nação que segundo especialistas caminha a taxas chinesas.É o crédito que permite aos pequenos proprietários ampliar os seus negócio e consequentemente a renda. A este processo de crescimento, Márcio Pochmann chama o governo de Lula de "social desenvolvimentismo", observando que houve mudanças significativas na economia e no desenvolvimento social . ( Pochmann, 2000)

Como observou Bolívar Lamounier;

"Sem inflação alta e com crescimento econômico, as sociedades ficam mais confiantes no futuro". ( Lamounier, 2010)

Nesta trajetória, espera-se que o país possa atingir, nos próximos anos, melhor grau de conforto, diminuir a desigualdade social e caminhar para uma erradicação da pobreza.

\section{Bibliografia}

ANTUNES, R. Adeus ao Trabalho-Ensaio sobre as Metamorfoses e a Centralidade do Mundo do Trabalho. São Paulo: Editora Cortez. 1995.

ALVES, G. O Novo (e Precário) Mundo do Trabalho: Reestruturação Produtiva e Crises do Sindicalismo. São Paulo: Editorial Boitempo, (2000).

BORGES, A. Mercado de Trabalho: mais de uma década de precarização. In: Drucke e Franco (ORGS). A Perda da Razão Social do Trabalho. São Paulo:Editorial Boitempo. 2007.

CARVALHO, R.Q. O Fordismo está vivo no Brasil. Estudos do CEBRAP. São Paulo, n.27, julho1990.

DEDECA, C.S. Rendimentos Previdenciários e Distribuição de Renda. In: Eduardo Fagnani E Márcio Pochmann.(Org) - Mercado e Trabalho , Relações Sindicais,Pobreza e Ajuste Fiscal. Cesit /UNICAMP. 2007.

DRUCK, M.G. Terceirização: Desfordizando a Fábrica. Um Estudo do Complexo Petroquímico. São Paulo: Editorial Boitempo. 2001

DRUCK,M.G.e FILGUEIRAS,- Política Social Focalizada e Ajuste Fiscal:as duas faces do governo Lula. Revista Katal.Florianópolis.v.10,n.1 p.24-34. 2007.

DRUCK, M.G. e FRANCO, T. Terceirização e Precarização : O binômio anti-social em indústrias. In:Franco e Druck(Org). A Perda da Razão Social do Trabalho.São Paulo: Editorial Boitempo. 2007. 
GRAMSCI. A.Maquiavel, a Política e o Estado Moderno. Rio de Janeiro: Civilização Brasileira. 1984.

HIRATA, H, (Org.). Sobre o Modelo Japonês. São Paulo Edusp. 1993.

HUMPHREY, J. Adaptando o modelo Japonês no Brasil. In: Hirata (Org.) Sobre o Modelo Japonês. São Paulo Edusp. 1993.

IANNI, O.Sociedade Global. Rio de Janeiro: Civilização Brasileira. 1992.

HOBSBAWM. E.. A Era dos Extremos: O Breve Século XX. São Paulo: Companhia das Letras. 1996.

LAMOUNIER, B. A Nova Classe Média. Entrevista a Revista Isto é. 25/Agosto 2010.

LEITE, M. Trabalho e Sociedade. São Paulo: Fundação Perseu Abramo. 2003.

LIPIETZ, A. Miragens e Milagres: Problemas de Industrialização no Terceiro Mundo. São Paulo: Nobel. 1988.

MATTOSO, Jorge. O Brasil Desempregado, São Paulo, Ed. Fundação Perseu Abramo.

POCHMANN, M. Revista Cult, 23/07/2010.

REGO, José Márcio e MARQUES, Rosa. Economia Brasileira. São Paulo: Saraiva 2000.

SILVA TEIXEIRA, F.C. Conquistar o campo. IN: Vargas e a questão agrária: a construção do fordismo possível. Diálogos, DHI/UEM, 02: 113-127.1998. 